\title{
XIII. On the Phænomena of volcanoes
}

\section{Sir Humphry Davy Bart. F.R.S.}

To cite this article: Sir Humphry Davy Bart. F.R.S. (1828) XIII. On the Phænomena of volcanoes, Philosophical Magazine Series 2, 4:20, 85-94, DOI: 10.1080/14786442808674733

To link to this article: http://dx.doi.org/10.1080/14786442808674733

曲 Published online: 10 Jul 2009.

Submit your article to this journal ש

Џ Article views: 3

Q View related articles $\sqsubset$ 
great abundance. Treated by the blowpipe with nitrate of cobalt, it assumes the fine blue colour which denotes alumina.

It dissolves almost entirely in caustic potash; and this soIntion affords by nitric acid a precipitate which is redissolved by an excess of acid. This last solution is precipitated by ammonia and by barytes.

These experiments sufficiently prove the presence of water, alumina, and sulphuric acid, and also the absence of silica.

The complete analysis by M. J. Dumas gives

Sulphuric acid................ 23

Alumina ....................... 30

Water ........................ 47

and this result agrees in the constituent principles and their proportions with those of the Websterite of Halle and Newhaven.

Thus, we perceive, as I have stated in the commencement of this notice, that this friable substance, which has more the appearance of an adventitious earthy mixture than of a mineral species, presents in its composition, an identity of principles, together with a precision in their proportions, rarely found in crystallized minerals, which indicate, by their solidity and limpidity, species completely limited. We see it also placed in geological positions and circumstances of which the constancy is no less striking. There is, however, between the Websterite of Autueil, and that of other localities, a slight difference of structure, which may serve to establish a variety in this species. It has the oolitic structure; and we may therefore distinguish it by the name of Oolitic Websterite of Auteuil.

XIII. On the Phanomena of Volcanoes. By Sir Humphry Davy, Bart. F.R.S.**

WHEN in the years 1807 and 1808 I discovered that the alkalies and the earths were composed of inflammable matter united to oxygen, a number of inquiries suggested themselves with respect to various parts of chemical science, some of which were capable of being immediately assisted by experiment, and others required for their solution a long series of observations, and circumstances obtained only with difficulty. Of the last kind were the inferences concerning the geological appearances connected with these discoveries.

The metals of the alkalies, and those of such of the earths as I had decomposed, were found to be highly combustible, and altered by air and water even at the usual temperatures

* From the Philosophical Transactions, for 1828. Part I. 
of the atmosphere; it was not possible, conseguently, that they should be found at the surface of the globe, but probable that they might exist in the interior: and allowing this hypothesis, it became easy to account for volcanic fires, by exposure of the metals of earths and alkalies to air and water ; and to explain, not only the formation of lavas, but likewise that of basalts and many other crystalline rocks, from the slow cooling of the products of combustion or oxidation of the newly-discovered substances.

I developed this opinion in a paper on the decomposition of the earths, published in 1808 ; and since 1812 I have endeavoured to gain evidence respecting it by examining volcanic phænomena of ancient and recent occurrence in various parts of Europe.

In this communication I shall have the honour of laying before the Royal Society some results of my inquiries. If they do not solve the problem respecting the cause of volcanic fires, they will, I trust, be found to offer some elucidations of the subject, and may serve as the foundation of future labours.

The active volcano on which $I$ have made my observations is Vesuvius; and there probably does not exist another so admirably fitted for the purpose: its vicinity to a great city; the facility with which it may be ascended in every season of the year; and the nature of its activity, - all offer peculiar advantages to the philosophic inquirer.

I had made several observations on Vesuvius in the springs of 1814 and 1815, which I shall refer to on a future occasion in these pages; but it was in December 1819, and January and February 1820, that the volcano offered the most favourable opportunity for investigation. On my arrival at Naples, December 4, I found that there had been a small eruption a few days before, and that a stream of lava was flowing with considerable activity from an aperture in the mountain a little below the crater. On the 5th I ascended the mountain, and examined the crater and the stream of lava. The crater emitted so large a quantity of smoke, with muriatic and sulphurous acid fumes, that it was impossible to approach it except in the direction of the wind; and it threw up every two or three minutes showers of red hot stones. The lava was flowing from an aperture about one hundred yards below it, being apparently forced out by elastic fluids with a noise like that made by the steam disengaged from a pressure engine; it rose, perfectly fluid, forming a stream of from five to six feet in diameter, and immediately fell, as a cataract, into a chasm about forty feet below, where it was lost under a kind of bridge formed of cooled lava; but it re-appeared sixty or seventy yards further 
down. Where it issued from the mountain, it was nearly white hot, and exhibited an appearance similar to that which is shown when a pole of wood is introduced into the melted copper of a foundry, its surface appearing in violent agitation, large bubbles rising, which in bursting produced a white smoke; but the lava became of a red colour, though still visible in the sunshine, where it issued from under the bridge. The force with which it flowed was so great, that the strength of the guide, a very stout young man, was insufficient to keep a long iron rod in the current. The whole of its course, with two or three interruptions where it flowed under a cooled surface, was nearly three quarters of a mile, and it threw off clouds of a white smoke. It smoked less as it cooled and became pasty; but even where it terminated in moving masses of scoria, smoke was still visible, which became more distinct whenever the scoria was moved, or the red hot lava in the interior exposed.

Having ascertained that it was possible to approach within four or five feet of the lava, and to examine the vapour immediately close to the aperture, I returned the next day, having provided the means of making a number of experiments on the nature of the lava, and of the elastic fluids with which it was accompanied. I found the aperture nearly in the same state as the day before, but the lava spread over a larger surface, forming an eddy in the hollow of the rock, over which it fell, from which it could be raised in an iron ladle more easily than from the current, and where there was much more facility of placing and withdrawing substances intended to be exposed to its agency.

One of the most inportant points to be ascertained was, whether any combustion was going on at the moment the lava issued from the mountain. There was certainly no appearance of more vivid ignition when it was exposed to air, nor did it glow with more intensity when it was raised into the air by an iron ladle. I put the circumstance, however, beyond the possibility of doubt: I threw some of the fused lava into a glass bottle furnished with a ground stopper, containing siliceous sand in the bottom: I closed it at the moment, and examined the air on my return. A measure of it mixed with a measure of nitrous gas gave exactly the same degree of diminution as a measure of common air which had been collected in another bottle on the mountain.

I threw upon the surface of the lava nitre, both in mass and in powder. After this salt had fused, there was a little increase of vividness in the ignition of the lava, but much too slight to be referred to pure combustible matter in any quantity; and on making the experiment on a portion of lava taken 
up in the ladle, it appeared that the disengagement of heat was partly owing to the peroxidation of the protoxide of iron, and to the combination of the alkali of the nitre with the earthy basis of the lava; for where the nitre had melted, the colour had changed from olive to brown. This conclusion was still further proved by the circumstance that chlorate of potash thrown upon the lava did not increase its degree of ignition so much as nitre. When a stick of wood was introduced into a portion of the lava so as to leave a little carbonaceous matter on its surface, nitre or chlorate of potassa then thrown upon it caused it to glow with great brilliancy. Some fused lava was thrown into water, and a glass bottle filled with water held over it to collect the gas disengaged; it was in very minute quantity only, and when analysed on my return proved to be common air a little less pure than that disengaged from the water by boiling. A wire of copper of $\frac{1}{2} \frac{t}{0}$ th of an inch in diameter, and a wire of silver of $\frac{1}{30}$ th, introduced into the lava near its source, were instantly fused: an iron rod of $\frac{1}{5}$ th of an inch, with a piece of iron wire of about $\frac{1}{50}$ th, were kept for five minutes in the eddy in the stream of lava; they were not fused; they did not produce any smell of sulphuretted hydrogen when acted on by muriatic acid. A tin-plate funnel filled with cold water was held in the fumes disengaged with so much violence from the aperture through which the lava issued: fluid was immediately condensed upon it, which was of an acid and subastringent taste. It did not precipitate muriate of baryta; but copiously precipitated nitrate of silver, and rendered the triple prussiate of potassa of a bright blue. When the same funnel was held in the white fumes above the lava where it entered the bridge, no fluid was precipitated upon it, but it became coated with a white powder which had the taste and chemical qualities of common salt, and proved to be this substance absolutely pure. A bottle of water holding about $\frac{3}{4}$ of a pint, with a long narrow neck, was emptied immediately in the aperture from which the vapours pressing out the lava issued, and the neck was immediately closed. This air examined on my return was found to give no absorption with solution of potassa; so that it contained no notable proportion of carbonic acid, and it consisted of 9 parts of oxygen and 91 of azote. There was not the least smell of sulphurous acid in the vapour from the aperture, nor were the fumes of muriatic acid so strong as to be unpleasant; but during the last quarter of an hour that I was engaged in these experiments, the wind changed, and blew the smoke from the crater upon the spot where I was standing: the sulphurous acid gas in the fumes was highly irritating to the organs of respiration, and I suf- 
fered so much from the exposure to them that I was obliged to descend; and the effect was not transient, for a violent catarrhal affection ensued, which prevented me for a month from again ascending the mountain.

On the 6th of January I made another visit to Vesuvius. I found the appearance of the lava considerably changed; the bocca from which it issued on the 5th of December was closed, and the current now flowed quietly and without noise from a chasm in the cooled lava about tbree hundred feet lower down. The heat was evidently less intense. I repeated my experiments with nitre with the same results, and exposed pure silver and platinum to the fused lava : they were not at all changed in colour.' I collected the sublimations from various parts of the cooled lava above. The rocks near the ancient bocca were entirely covered with white, yellow, and reddish saline substances. I found one specimen of large saline crystals in a cavity, which had a slight tint of purple: this examined, proved to be common salt with a minute portion of muriate of cobalt. The other sublimations consisted of common salt in great excess, much chloride of iron, some sulphate of soda; and by the test of muriate of platinum, there appeared to exist in them a small quantity of sulphate or muriate of potassa; and a solution of ammonia detected the presence of a minute quantity of the oxide of copper.

During the months of January and February I made several visits to the top of Vesuvius: I shall not particularize them all; but.shall mention only such as afforded me some new observations. On the 26 th of January, the lava was seen nearly white hot through a chasm near the place where it flowed from the mountain. I threw nitre upon it in large quantities through this chasin, in the presence of H.R.H. the Prince of Denmark, whom I had the honour of accompanying in this excursion to the mountain, and my friend the Cavaliere Monticelli: there was no more increase of ignition than when the experiment was made on lava exposed to the free air. The appearance of the sublimations was now considerably changed : those near the aperture were coloured green and blue by salts of copper; but there was still a great quantity of muriate of iron. I have mentioned, that on the 5th the sublimate of the lava was pure chloride of sodium: in the sublimate of January 6th, there were both sulphate of soda and indications of sulphate of potassa. In the sublimates that I collected on the 26th, the sulphate of soda was in much larger quantities, and there was much more of a salt of potassa. From the 5th of December to the 20th of February, the lava flowed in larger or smaller quantities, so that at night a stream of ignited mat-

New Series. Vol. 4. No. 20. Aug. $1828 . \quad$ N ter 
ter was always visible, more or less interrupted by cooled lava. It changed its direction according to the obstacles it met with; and never, according to appearances, extended so much as a mile from its source. During the whole of this time the craters, of which there were two, were in activity. The large crater threw up showers of ignited ashes and stones to a height apparently of from 200 to 500 feet; and from a smaller crater, to the right of the large one on the side of Naples, steam arose with great violence. Whenever the crater could be approached it was found incrusted with saline incrustations; and the walk to the edge of the small crater on the 6th of January was through a mass of loose saline matter, principally common salt coloured by muriate of iron, in which the foot sunk to some depth. It was easy, even at a great distance, to distinguish between the steam disengaged by one of the craters, and the earthy matter thrown up by the other. The steam appeared white in the day, and formed perfectly white clouds, which reflected the morning and evening light of the purest tints of red and orange. The earthy matter always appeared as a black smoke, forming black clouds; and in the night it was highly luminous at the moment of the explosion.

On the 20th of February, the small crater which had been disengaging stean and elastic matter, began to throw out showers of stones; and both craters from the 20th to the 23rd were more than usually active. On the night of the 23rd, at half past 11 o'clock, being in my bed-room at Chiatimone, Naples, I heard the windows shake; and going to the window, I saw ascending from Vesuvius a column of ignited matter to a height at least equal to that of the mountain from its base; and the whole horizon was illuminated, notwithstanding the brightness of the moon, with direct volcanic light, and that reflected from the clouds above the column of ignited matter. Several eruptions of the same kind, but upon a smaller scale, followed at intervals of a minute and a half or two minutes; but there were no more symptoms of earthquake, nor did I hear any noise. On observing the lava, it appeared at its origin much broader and more vivid; and it was evident that a fresh stream had broken out to the right of the former one. On the morning of the 24th I visited the mountain; it was not possible to ascend to the top, which was covered with clouds, nor to examine the orifice from which the lava issued. The stream of lava near the place where it terminated was from 50 to 100 feet broad. It had precisely the same appearances as the lava which had been so long running. I collected the saline matter condensed upon some of the masses of scoria which were carried along by the current and deposited on the 
edge of the stream; they proved to be the same in the nature of their constituent parts as those of the lava of the 26th of January, but with a larger proportion of sulphate of soda, and a smaller proportion of muriate of iron; and I have no doubt that the dense white smoke which was emitted in immense columns by the lava during the whole of its course, was produced by the same substances.

I shall now mention the state of the volcano at some other periods.

When I was at Naples in May 1814, the crater had the appearance of an immense funnel, closed at the bottom, with many small apertures emitting steam; and on the side towards Torre del Greco, there was a large aperture from which flame issued to a height of at least 60 yards, producing a most violent hissing noise. This phænomenon was constant during the three weeks I remained at Naples. It was impossible to approach sufficiently near the flame to ascertain the results of the combustion; but a considerable quantity of steam ascended from it. When the wind blew the vapours upon us, there was a distinct smell both of sulphurous and muriatic acids. There was no indication of corbonaceous matter from the colour of the smoke; nor was any deposited upon the yellow and white saline matter which surrounded the crater, and which I found to be principally sulphate and muriate of soda, and muriate of iron: in some specimens there was a considerable quantity of muriate of ammonia.

In March 1815, the appearances presented by the crater were entirely different. There was no aperture in the crater; it was often quiet for minutes together, and then burst out into explosions with considerable violence, sending fluid lava and ignited stones and ashes to a considerable height, many hundred feet, in the air.

These eruptions were preceded by subterraneous thunder, which appeared to come from a great distance, and which sometimes lasted for a minute. During the four times that $I$ was upon the crater in the month of March, I had at last learnt to estimate the violence of the eruption from the nature of the sound: loud and long continued subterraneous thunder indicated a considerable explosion. Before the eruption the crater appeared perfectly tranquil; and the bottom, apparently without an aperture, was covered with ashes. Soon, indistinct rumbling sounds were heard as if at a great distance; gradually the sound approached nearer, and was like the noise of artillery fired under our feet. The ashes then began to rise and to be thrown out with smoke from the bottom of the crater; and lastly, the lava and ignited matter was ejected with a most 
violent explosion. I need not say that when I was standing on the edge of the crater witnessing this phænomenon, the wind was blowing strongly from me: without this circumstance it would have been dangerous to have stood on the edge of the crater; and whenever from the loudness of the thunder the eruption promised to be violent, I always ran as far as possible from the seat of danger.

As soon as the eruption had taken place, the ashes and stones which rolled down the crater seemed to fill up the aperture, so that it appeared as if the ignited and elastic matter were discharged laterally; and the interior of the crater assumed the same appearance as before.

I shall now offer some observations on the theory of these phænomena. It appears almost demonstrable that none of the chemical causes anciently assigned for volcanic fires can be true. Amongst these, the combustion of mineral coal is one of the most current; but it seems wholly inadequate to account for the phænomena. However large a stratum of pit-coal, its combustion under the surface could never produce violent and extensive heat; for the production of carbonic acid gas, when there was no free circulation of air, must tend constantly to impede the process: and it is scarcely possible that carbonaceous matter, if such a cause existed, should not be found in the lava, and be disengaged with the saline or aqueous products from the bocca or craters. There are many instances in England of strata of mineral coal which thave been long burning; but the results have been merely baked clay and schists, and it has produced no result similar to lava.

If the idea of Lemery were correct, that the action of sulphur on iron may be a cause of volcanic fires, sulphate of iron ought to be the great product of the volcano; which is known not to be the case; and the heat produced by the action of sulphur on the common metals, is quite inadequate to account for the appearances. When it is considered that volcanic fires occur and intermit with all the phænomena that indicate intense chemical action, it seems not unreasonable to refer them to chemical causes. But for phænomena upon such a scale, an immense mass of matter must be in activity, and the products of the volcano ought to give an idea of the nature of the substances primarily active. Now what are these products? Mixtures of the earths in an oxidated and fused state, and intensely ignited; water and saline substances, such as might be furnished by the sea and air, altered in such a manner as might be expected from the formation of fixed oxidated matter. But it may be said, if the oxidation of the metals of the earths be the causes of the phrenomena, some of these substances ought occasionally 
occasionally to be found in the lava, or the combustion ought to be increased at the moment the materials passed into the atmosphere. But the reply to this objection is, thar it is evident that the changes which occasion volcanic fires, take place in immense subterranean cavities; and that the access of air to the acting substances occurs long before they reach the exterior surface.

There is no question but that the ground under the solfaterra is hollow, and there is scarcely any reason to doubt of a subterraneous communication between this crater and that of Vesuvius: whenever Vesuvius is in an active state, the solfaterra is comparatively tranquil. I examined the bocca of the solfaterra on the 21 st of February 1820, two days before the activity of Vesuvius was at its height: the columns of steam which usually arise in large quantities when Vesuvius is tranquil, were now scarcely visible, and a piece of paper thrown into the aperture did not rise again; so that there was every reason to suppose the existence of a descending current of air*. The subterraneous thunder heard at such great distances under Vesuvius, is almost a demonstration of the existence of great cavities below filled with aëriform matter : and the same excavations which in the active state of the volcano throw out during so great a length of time immense volumes of steam, must, there is every reason to believe, in its quiet state become filled with atmospheric air $\uparrow$.

To what extent subterraneous cavities may exist even in common rocks, is shown in the limestone caverns of Carniola, some of which contain many hundred thousand cubical feet of air; and in proportion as the depth of an excavation is greater, so is the air more fit for combustion.

The same circumstance which would give alloys of the metals of the earths the power of producing volcanic phænomena, namely, their extreme facility of oxidation, must likewise prevent them from ever being found in a pure combustible state in the products of volcanic eruptions; for before they reach the external surface, they must not only be exposed to the air in the subterranean cavities, but be propelled by steam; which must possess, under the circumstances, at least the same facility of oxidating them as air. Assuming the hypothesis of the

* In 1814, in 1815, and in January 1819, when Vesuvius was compara. tively tranquil, I observed the solfaterra in a very active state, throwing up large quantities of steam and some sulphuretted hydrogen.

+ Vesuvius is a mountain admirably fitted, from its form and situation, for experiments on the effect of its attraction on the pendulum: and it would be easy in this way to determine the problem of its cavities. On Etna, the problem might be solved on a larger scale. 


\section{Prof. Hare's Rationale on the Difficulty of separating}

existence of such alloys of the metals of the earths as may burn into lava in the interior, the whole phænomena may be easily explained from the action of the water of the sea and air on those metals; nor is there any fact or any of the circumstances which I have mentioned in the preceding part of this paper, which cannot be easily explained according to that hypothesis. For almost all the volcanoes in the old world of considerable magnitude are near, or at no considerable distance from the sea: and if it be assumed that the first eruptions are produced by the action of sea water upon the metals of the earths, and that considerable cavities are left by the oxidated metals thrown out as lava, the results of their action are such as might be anticipated; for after the first eruptions, the oxidations which produce the subsequent ones may take place in the caverns below the surface; and when the sea is distant, as in the volcanoes of South America, they may be supplied with water from great subterranean lakes; as Humboldt states that some of them throw up quantities of fish.

On the hypothesis of a chemical cause for volcanic fires, and reasoning from known facts, there appears to me no other adequate source than the oxidation of the metals which form the bases of the earths and alkalies; but it must not be denied that considerations derived from thermometrical experiments on the temperature of mines and of sources of hot water, render it probable that the interior of the globe possesses a very high temperature: and the hypothesis of the nucleus of the globe being composed of fluid matter, offers a still more simple solution of the phænomena of volcanic fires than that which bas been just developed.

Whatever opinion may be ultimately formed or adopted on this subject, $I$ hope that these inquiries on the actual products of a volcano in eruption will not be without interest for the Royal Society.

XIV. Rationale of the Difficulty of separating Plane Surfaces by a Blast, in certain Cases. By R. HARE, M.D. Professor of Chemistry in the University of Pennsylvania.*

THE phænomenon above alluded to, is usually illustrated by means of two discs, into the centre of one of which, a tube is fastened, so that on blowing through the tube, the current is arrested by the other moveable disc. Under these circumstances, the moveable disc is not removed as would be naturally expected. Supposing the diameter of the discs to

* Communicated by the Author. 